\title{
PERCEPÇÕES DE ESTUDANTES DO 6 ANO DO ENSINO FUNDAMENTAL SOBRE OS MORCEGOS (MAMMALIA, CHIROPTERA) EM LEME (SP)
}

Ana Beatriz Ligo ${ }^{1}$

Renata Mello Giona ${ }^{2}$

Resumo: Os morcegos são cercados de mitos e superstições, fazendo com que grande parte da sociedade apresente aversão com relação a esses animais. O estudo da percepção ambiental permite identificar o modo como a sociedade enxerga o meio ambiente, assim como seus interesses e crenças. Este trabalho teve como objetivo analisar a percepção dos alunos do $6^{\circ}$ ano do ensino fundamental com relação aos morcegos. Foram entrevistados 100 alunos entre 11 e 13 anos. A entrevista foi realizada por meio de questionário com quatro questões fechadas e uma aberta. Foi possível identificar que embora os alunos possuam um bom conhecimento sobre morcegos, uma parcela considerável ainda possui informações equivocadas sobre esse grupo, demonstrando que programas de Educação Ambiental são necessários para uma melhor conscientização ambiental.

Palavras-chave: Percepção Ambiental; Morcegos; Educação Ambiental; Quirópteros. 


\section{Introdução}

As mudanças provocadas pela ação do homem na natureza, assim como a resposta do meio ambiente como consequência dessas ações, têm se tornado motivo de preocupação para muitas pessoas. Assim, diversos pesquisadores procuram meios para a sensibilização da sociedade com relação aos problemas ambientais (BEZERRA et al., 2014). Além disso, grande parte da sociedade ainda desconhece a fauna brasileira, possuindo informações distorcidas, cercadas de mitos e superstições. Tais crendices, passadas de geração em geração, podem se tornar um empecilho à conservação da biodiversidade, pois incentivam a caça, perseguição e o desenvolvimento de uma percepção fundada em repúdio e preconceito (VIEIRA et al., 2014). Nesse sentido, os morcegos sofrem com a falta de informação acerca da biologia que os caracterizam ou com a distorção sobre alguns de seus aspectos que, nesse último caso, vem sendo disseminado pela mídia de forma negativa, resultando em um preconceito cultural em relação a esses animais (FILHO et al., 2010).

Considerando todos os grupos de mamíferos, o grupo dos morcegos aparenta estar mais envolvido com desinformação, folclore e mito ao passo que informações ecológicas a respeito desses animais são pouco divulgadas, indicando a necessidade de estratégias didático-pedagógicas abordando de forma científica a importância e necessidade de conservação desse grupo (SCAVRONI et al., 2000).

A percepção ambiental é definida, de acordo com Faggionato (2007), como uma tomada de consciência do ser humano com relação ao ambiente, ou seja, é a ação de perceber o ambiente do qual faz parte. A percepção, identificação e classificação da fauna pela sociedade são influenciadas pelo significado emotivo e pelas atitudes construídas culturalmente direcionadas aos animais (NOLAN; ROBBINS, 2001). Seu estudo possibilita compreender as relações entre ser humano e meio ambiente, garantindo um processo de sensibilização, julgamento e conduta adequada (KANDA et al., 2014). Além disso, o diagnóstico da percepção ambiental é imprescindível no desenvolvimento de projetos de conscientização ambiental (SOUSA et al., 2017). De acordo com Vieira et al. (2014), a compreensão das interações que permeiam a relação entre homem-animal-meio ambiente, combinado com o conhecimento científico no ensino de ciências, é um passo fundamental para determinar ferramentas visando a sensibilização da população no que diz respeito à conservação da natureza.

De acordo com a Política Nacional de Educação Ambiental, Art 1ํ.:

Entendem-se por Educação Ambiental os processos por meio dos quais o indivíduo e a coletividade constroem valores sociais, conhecimentos, habilidades, atitudes e competências voltadas para a conservação do meio ambiente, bem de uso comum do povo, essencial à sadia qualidade de vida e sua sustentabilidade (BRASIL,1999). 
Para o desenvolvimento de atividades em Educação Ambiental, é necessário o conhecimento da realidade local, por exemplo, como os indivíduos percebem o ambiente em que se encontram, seus saberes, valores, hábitos, tendências e necessidades. Desse modo, o estudo da percepção ambiental é uma ferramenta que fornece essas informações, diagnosticando de forma eficaz a realidade com a qual será trabalhada, tornando-se uma etapa importante para a elaboração de atividades e programas em Educação Ambiental (CUNHA; ZENI, 2007). Para Estevam e Gaia (2017), nos trabalhos de Educação Ambiental, o conhecimento prévio das concepções ambientais do público-alvo pode nortear as ações educativas produzindo um conhecimento significativo, caso contrário tais medidas podem ser limitadas ou ineficientes. Segundo Leal e Nunes (2003), para a execução de projetos de Educação Ambiental que valorizem as vivências locais e abordem o meio ambiente de forma totalizadora, é preciso conhecer as ideias previas que o público-alvo possui com relação ao ambiente. Considerando a percepção do grupo envolvido, é possível a execução de ações educativas direcionadas à comunidade, capazes de preservar a qualidade de vida e valorizar os saberes populares que normalmente são deixados de lado no espaço escolar, elementos importantes no desenvolvimento da conscientização dos problemas ambientais. Com relação aos morcegos, de acordo com Paiva (2010), a Educação Ambiental é um meio de fornecer informações acerca desses animais e chamar a atenção para as ameaças impostas a esse grupo, a fim de melhorar a percepção que a sociedade tem sobre eles. Para Uieda (2011), com trabalhos de divulgação e conscientização pode ser possível solucionar os conflitos entre a sociedade e os morcegos, especialmente quando os trabalhos são direcionados para crianças do Ensino Fundamental.

Alguns estudos têm sido realizados demonstrando a importância da pesquisa da percepção ambiental de crianças e jovens, especialmente quando se trata de animais menos populares e vistos como indesejáveis. Exemplos são os estudos de Prokop e Tunnicliffe (2008) que abordaram a percepção dos alunos com relação a aranhas e morcegos e Knight (2008), que investigou a percepção sobre morcegos, cobras e aranhas.

Dessa forma, este trabalho teve como objetivo conhecer a percepção que os alunos do $6^{\circ}$ ano do ensino fundamental têm sobre os morcegos, incluindo conhecimentos prévios, sentimentos, mitos e crenças populares. Esse público foi escolhido pois ainda não haviam aprendido sobre esses animais nas aulas de ciências, possuindo, portanto, apenas um conhecimento superficial sobre o assunto. A pesquisa foi realizada em abril de $2018 \mathrm{em}$ uma escola estadual e contou com a participação de 100 alunos que compunham quatro turmas de $6^{\circ}$ ano do ensino fundamental. Tal conhecimento é importante para nortear o professor na melhor escolha dos métodos de ensino-aprendizagem, assim como em uma melhor abordagem do tema. 


\section{Material e Métodos}

A pesquisa foi desenvolvida em uma escola estadual localizada na cidade de Leme, estado de São Paulo. A escola se situa na região periférica e atende crianças e jovens dos bairros vizinhos. Oferece ensino fundamental II (6ํㅡㅁ ${ }^{\circ}$ ano).

Para a coleta de dados, foi aplicado um questionário contendo 05 questões, sendo 04 questões fechadas e 01 questão aberta (Apêndice 1). Nas questões fechadas, houve a opção "Outros", em que o aluno poderia inserir uma resposta que não estava presente nas alternativas apresentadas. As questões foram baseadas nos trabalhos de Gomes et al. (2017), Gonçalves et al. (2016) e Novaes et al. (2008) e abordaram assuntos sobre a biologia, ecologia, importância ecológica e mitos acerca de morcegos.

Os questionários foram respondidos por quatro turmas $(A, B, C$ e $D)$ do $6^{\circ}$ ano do ensino fundamental, totalizando 100 alunos. Os alunos apresentavam faixa etária entre 11 e 13 anos.

\section{Resultados e Discussão}

A primeira pergunta do questionário se refere à classificação dos morcegos e as respostas estão representadas na Figura 1. Apesar da maioria dos estudantes os classificarem de maneira correta, ainda é relevante a quantidade de alunos que consideram esses animais como sendo aves (29\%).

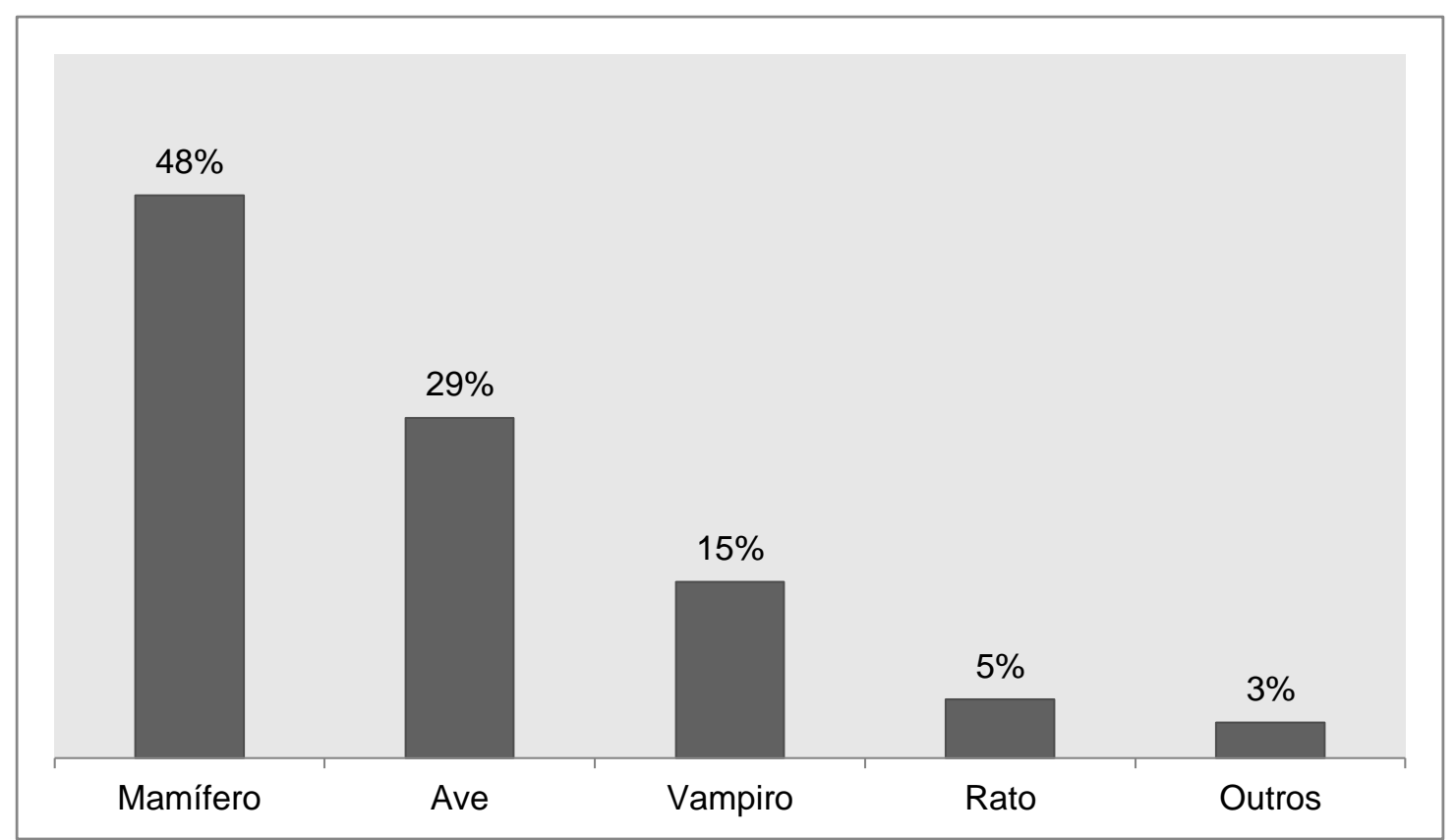

Figura 1: Concepções dos alunos sobre o que é um morcego. Fonte: Autoras (2018). 
Tal resultado possivelmente se deve a capacidade de voo dos morcegos. Segundo Peracchi et al. (2011), os morcegos fazem parte de uma das ordens mais características de mamíferos, sendo os únicos a possuírem estruturas especializadas que possibilitam um voo verdadeiro. Além disso, Gomes et al. (2017) relatam que a ausência de contato com esses animais, especialmente por terem hábito noturno, impede a observação de sua morfologia, cuja presença de pelos é uma característica marcante dos mamíferos.

A terceira classificação mais citada foi "vampiro" (15\%). Os meios de comunicação interferem na percepção da sociedade sobre os morcegos, tendo como destaque a forte relação entre esse grupo e personagens vampiros apresentada por filmes, novelas e desenhos, em muitos casos exaltando-se apenas aspectos negativos (CAPPARROS; JUNIOR, 2015). A opção "Rato" foi menos assinalada, talvez porque a crença popular de que eles são ratos velhos que desenvolveram asas seja menos disseminada entre as crianças ou na região estudada. Na categoria "outros" foram citados: "é um animal assustador", "bicho" e "carnívoro".

A segunda pergunta se refere à reação do aluno ao encontrar um morcego, as respostas estão representadas na Figura 2.

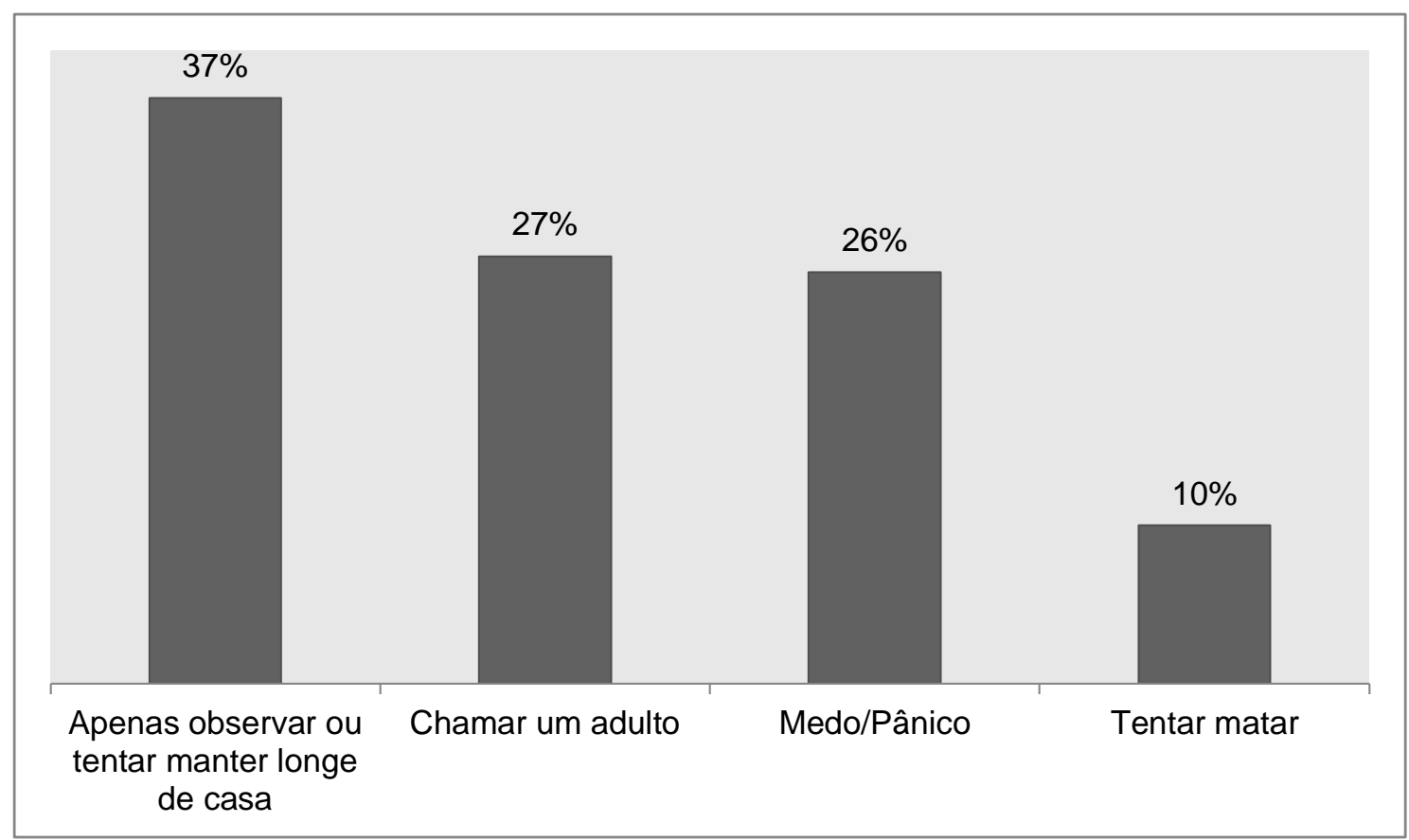

Figura 2: Reações dos alunos ao encontrar um morcego. Fonte: Autoras (2018).

O alto número de estudantes que declararam que ao encontrar um morcego apenas observariam ou manteriam longe de casa é um resultado positivo, visto que a matança desses animais por conta de superstições ou aversão é uma das causas do declínio populacional de algumas espécies. A 
segunda opção mais votada foi "chamar um adulto", o que era esperado, já que os entrevistados são crianças de 11 a 13 anos que muitas vezes acionam um responsável quando se deparam com algo inesperado. Alguns estudantes relataram sentir medo/pânico (26\%) e possivelmente tal resultado se dá como consequência das crenças de que os morcegos atacam o pescoço das pessoas, assim como nos filmes e desenhos, ou que todos disseminam doenças. Do total de alunos, $10 \%$ relataram que matariam o animal, entretanto, é importante destacar que eles fazem parte da fauna brasileira, e por conta disso são protegidos pela lei federal 9605/98 (BRASIL, 1998).

Esses resultados coincidem com os encontrados por Gomes et al. (2017) em entrevistas com moradores de área urbana, em que a maioria (49\%) relatou que apenas observaria, 37\% teriam reações de medo/pânico, 13\% matariam e $1 \%$ acionariam as autoridades. Cabe ressaltar que nesta pesquisa não foi apresentada a alternativa "chamar as autoridades" e sim "chamar um adulto", pois o público-alvo eram estudantes de 11 a 13 anos.

Quanto aos hábitos alimentares, as respostas estão representadas na Figura 3.

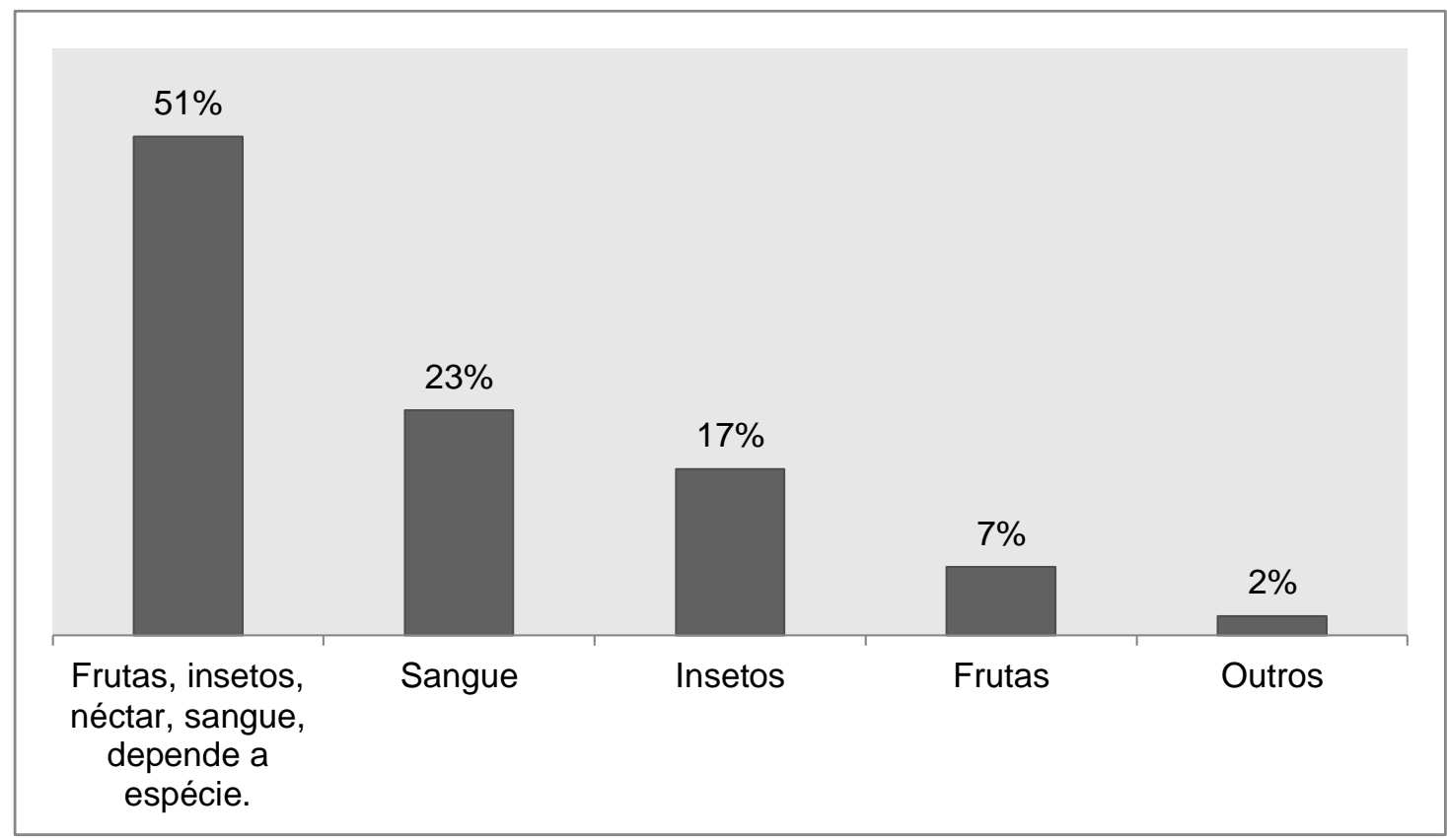

Figura 3: Concepções dos alunos sobre a alimentação dos morcegos.

Fonte: Autoras (2018).

O grande número de alunos que acredita que a alimentação dos morcegos varia de acordo com a espécie pode ter sido resultado do contato com esses animais em áreas urbanas. De acordo com Filho et al. (2010), por consumirem plantas e insetos existentes nas cidades e habitarem construções humanas, esses animais estão em constante interação com o homem. Segundo Lima (2008), são reconhecidas 63 espécies vivendo em áreas urbanas. 
Apesar de a maioria responder que a alimentação depende da espécie, ainda é relevante o número de estudantes que acreditam que os morcegos se alimentam apenas de sangue. A associação desse grupo com o hábito de consumir sangue possivelmente é devido à ligação desses animais com o vampirismo, que é muito disseminado pela mídia. Entretanto, sabe-se que de todas as espécies de quirópteros, apenas três são hematófagas. Em um estudo com crianças de 10 a 15 anos, Kubiatko e Prokop (2007) relataram que 30\% deles acreditam que os morcegos alimentam-se apenas de sangue, não sendo especificado se sangue humano ou de outros animais. Já Prokop e Tunnicliffe (2008), aplicaram um questionário para crianças de 10 a 16 anos e $37 \%$ dos entrevistados também acreditam que a dieta principal dos morcegos é sangue. Em "Outros" os alunos responderam: "apenas insetos e frutas" e "peixes pequenos".

Sobre a importância dos morcegos ao meio ambiente, as respostas estão representadas na Figura 4.

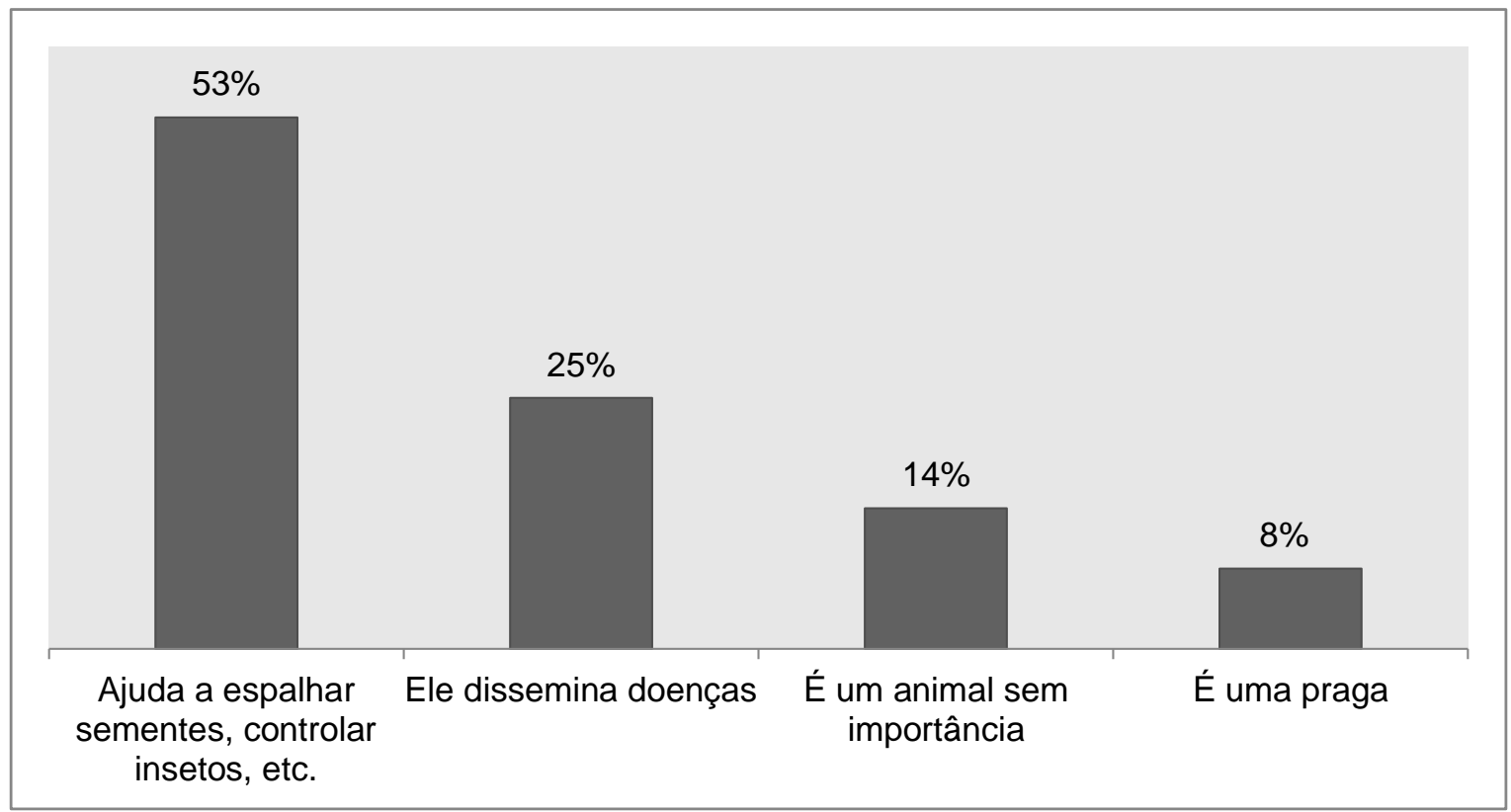

Figura 4: Concepções dos alunos sobre a importância dos morcegos ao meio ambiente. Fonte: Autoras (2018).

A maioria dos estudantes (53\%) acredita que os morcegos desempenham a função de dispersar sementes, controlar insetos etc. Esse resultado pode estar relacionado com a questão anterior, em que foi indagada qual a alimentação desses animais. Muitos estudantes os avistam em árvores frutíferas do bairro ou ao redor de luzes capturando insetos, e isso pode ter influenciado a percepção sobre a importância que eles têm na natureza. Os morcegos desempenham importantes funções no meio ambiente, atuando como dispersores de sementes, polinizadores e controladores de insetos (KUNZ et al., 2011), contribuindo para a manutenção de ecossistemas saudáveis e funcionais, o que resulta na manutenção de processos vitais como 
regulação climática, ciclagem de nutrientes, filtração de água e controle de erosão.

Entretanto, 25\% dos alunos entrevistados acreditam que eles apenas disseminam doenças. De fato, esses animais podem estar envolvidos na transmissão de algumas doenças, como a raiva e a histoplasmose, que é uma micose causada por fungo dimórfico, e a transmissão ocorre após a exposição a ambientes contaminados com o fungo Histoplasma capsulatum, particularmente cavernas onde habitam morcegos, galinheiros, etc. (FERREIRA; BORGES, 2009). Contudo, a ideia de que todos os morcegos estão infectados e transmitem doenças, é equivocada.

Além disso, $14 \%$ dos alunos acreditam que morcegos sejam animais sem importância. Tal resultado pode estar relacionado com as crenças populares que muitas vezes ressaltam apenas os aspectos negativos do grupo, além da mídia que acaba não expondo os benefícios que oferecem ao meio ambiente e ao homem.

Do total de alunos, $8 \%$ acreditam que os morcegos são uma praga. Para Esbérard et al. (1996), é prejudicial a frequente associação feita entre esses animais e as pragas urbanas, sendo de grande importância destacar sempre a relevância dos morcegos que atuam na polinização, dispersão de sementes e controle de insetos.

As respostas da questão 05 estão representadas no Quadro 1, em que as citações foram categorizadas. Nessa questão, os alunos relataram histórias populares que conheciam, além de hábitos que eles acreditam que os morcegos tenham. Nesse momento, mitos e crenças populares foram relatas, assim como características científicas, muitas das quais já citadas em questões anteriores.

Quadro 1: Citações dos alunos dos 6ํanos sobre as histórias populares e hábitos dos morcegos.

\begin{tabular}{|c|c|c|}
\hline CATEGORIA & EXEMPLO & FREQUÊNCIA \\
\hline \multirow{4}{*}{ Alimentação } & "Chupam o sangue das pessoas" & 06 \\
\cline { 2 - 3 } & "Chupam sangue" & 11 \\
\cline { 2 - 3 } & "Eles gostam de sangue, principalmente de criança \\
porque o sangue é doce" & 01 \\
\cline { 2 - 3 } & "Se tiver um machucado sangrando, os morcegos vêm e \\
\cline { 2 - 3 } & chupam o sangue" & 01 \\
\cline { 2 - 3 } & "A alimentação depende da espécie" & 03 \\
\cline { 2 - 3 } & "Comem insetos" & 06 \\
\cline { 2 - 3 } & "Comem frutas" & 01 \\
\cline { 2 - 3 } & "Comem carniça" & 01 \\
\hline
\end{tabular}

Revbea, São Paulo, V. 14, № 3: 169-184, 2019. 


\begin{tabular}{|c|c|c|}
\hline CATEGORIA & EXEMPLO & FREQUÊNCIA \\
\hline \multirow{7}{*}{ Classificação } & "São vampiros" & 06 \\
\hline & "Morcegos não viram vampiros" & 02 \\
\hline & "É um mamífero" & 04 \\
\hline & "Os morcegos são iguais aos besouros" & 01 \\
\hline & "Primeiro são ratos e depois viram morcegos" & 01 \\
\hline & "Falam que são ratos" & 03 \\
\hline & "É uma ave" & 01 \\
\hline \multirow{3}{*}{ Nocividade } & "Transmitem doenças" & 08 \\
\hline & "São perigosos" & 09 \\
\hline & "Não fazem nada" & 01 \\
\hline \multirow{8}{*}{ Hábitos } & "Dormem durante o dia e ficam acordados à noite" & 13 \\
\hline & "Á noite eles saem para caçar" & 03 \\
\hline & "Vivem no escuro" & 09 \\
\hline & "Não gostam do sol" & 03 \\
\hline & "A luz faz mal para os olhos dos morcegos" & 02 \\
\hline & "Se o morcego sair no sol, ele morre" & 01 \\
\hline & "À noite eles saem para assustar as pessoas" & 01 \\
\hline & "Ele não pode ficar no sol porque a pele dele queima" & 03 \\
\hline \multirow{4}{*}{ Hábitat } & "Vivem em cavernas" & 05 \\
\hline & "Moram nas árvores" & 06 \\
\hline & "Moram em lugares abandonados" & 01 \\
\hline & "Moram em lugares fechados e escuros" & 03 \\
\hline \multirow{9}{*}{ Comportamento } & "Dormem de ponta cabeça" & 05 \\
\hline & "Vi um morcego botando ovos" & 01 \\
\hline & "Se bater com algo longo nos morcegos, eles morrem" & 01 \\
\hline & "Sabem a direção com suas orelhas" & 01 \\
\hline & "Conseguem voar pelo barulho" & 01 \\
\hline & "Defecam sementes" & 02 \\
\hline & "Derrubam as sementes das frutas" & 01 \\
\hline & "Eles mordem as coisas" & 01 \\
\hline & Se balançarmos uma vara de pescar, atraímos os morcegos & 01 \\
\hline \multirow{3}{*}{ Características } & "São cegos" & 02 \\
\hline & "São pretos" & 01 \\
\hline & "Eles têm sangue preto e vermelho" & 01 \\
\hline \multirow{5}{*}{$\begin{array}{c}\text { Afetividade/ } \\
\text { Repulsa/ } \\
\text { Indiferença }\end{array}$} & "Eles são fofos" & 01 \\
\hline & "A presença dele é muito ruim" & 01 \\
\hline & "São feios" & 01 \\
\hline & "É um animal sem nenhuma importância específica" & 01 \\
\hline & "São nojentos" & 01 \\
\hline \multirow{4}{*}{ Mídia } & "Hotel Transilvânia" & 05 \\
\hline & "Só vi morcegos em desenhos" & 01 \\
\hline & "Vi um morcego no filme Drácula" & 02 \\
\hline & "Vi um morcego no filme do Batman" & 01 \\
\hline
\end{tabular}

Fonte: Autoras (2018). 
A categoria "Alimentação" conta com 35 citações, sendo a maioria com relação ao hábito de consumir sangue. A hematofagia é amplamente divulgada quando se trata dos morcegos. Entretanto, das espécies conhecidas, apenas três consomem sangue. Além disso, algumas citações podem ter caráter sensacionalista como em "Chupam o sangue das pessoas", o que pode ter relação com a associação muito disseminada pela mídia entre esse grupo e os vampiros. Nessa categoria, têm destaque as citações "Eles gostam de sangue, principalmente de criança porque o sangue é doce" e "Se tiver um machucado sangrando, os morcegos vêm e chupam o sangue", essas crenças podem ter sido transmitidas através de gerações na família.

$\mathrm{Na}$ mesma categoria, houve um relato de que os morcegos consomem carniça. Em pesquisa realizada por Gomes et al. (2017), um dos entrevistados também citou o consumo de animais mortos, além de lixo. Entretanto, de acordo com os mesmos autores, isso pode estar relacionado com a crença de que os morcegos são ratos velhos e a associação dessa dieta com a presença desses animais em depósitos de lixo ou consumindo detritos e matéria orgânica.

$\mathrm{Na}$ categoria "Classificação", 06 estudantes citaram o mito do "Vampiro". Os quirópteros são frequentemente associados à figura do vampiro e tal associação é reforçada pela mídia por meio de filmes e desenhos. O mito de que são ratos velhos foi citado 04 vezes. Essa é uma crença popular muito comum, e de acordo com Reis et al. (2007), o próprio nome morcego é derivado do latim muris (rato) e coecus (cego). Além disso, foi citado que "os morcegos são iguais aos besouros", tal percepção pode ser resultado da observação de ambos os animais voando no escuro e pela impossibilidade de identificação de suas cores e morfologias.

$\mathrm{Na}$ categoria "Nocividade" houve um relevante número de citações como "Eles são perigosos" e "Transmitem doenças". Sabe-se que esses animais participam do ciclo de diversas doenças, entre elas a raiva e a histoplasmose. Porém, a crença de que todos transmitem doenças é errônea. Comumente, esses aspectos negativos são mais evidenciados, em detrimento de seu benefício em relação ao meio ambiente e ao homem.

O hábito noturno foi o mais citado na categoria "Hábitos". De acordo com Peracchi et al. (2011), a maior parte das espécies de morcegos repousam durante o dia e se alimentam à noite, saindo de seus abrigos diurnos ao entardecer. Um dos alunos relatou que eles "saem à noite para assustar as pessoas", confirmando que a aversão a esse grupo pode ter relação com seus hábitos peculiares. Outra característica citada foi a aversão à luz que aqui tem caráter fantasioso e possivelmente influenciado pelos filmes, como em " $S$ e o morcego sair no sol, ele morre" e "Ele não pode ficar no sol porque a pele dele queima".

Na categoria "Hábitats", alguns locais como cavernas, árvores e locais abandonados foram citados. Segundo Peracchi et al. (2011), os morcegos se 
abrigam em cavernas, locas de pedra, minas, fendas e cavidades em diversos locais, folhagens modificadas por eles ou não e construções humanas.

Quanto ao comportamento, os entrevistados citaram o fato desses animais dormirem de cabeça para baixo. Segundo Laurindo e Novaes (2015), um dos motivos para esse comportamento seria por conta da maior facilidade de alçar voo, pois devido à força da gravidade, quando eles se soltam recebem impulso para iniciar o voo sem precisar utilizar muita energia.

Um dos entrevistados também relatou que viu um morcego botando ovos, isso pode estar relacionado com a frequente classificação desses animais como pertencentes à classe das aves por conta da observação desses animais em voo. De acordo com Peracchi et al. (2011), os morcegos são os únicos mamíferos com capacidade voo verdadeiro.

Houve duas citações referentes à orientação desses animais: "Sabem a direção com suas orelhas" e "Conseguem voar pelo barulho". A maioria dos morcegos possui a capacidade de emitir sons de alta frequência e de receber esses sons novamente que retornam ao encontrar um objeto. Dessa forma, se orientam pela emissão e percepção dos sons de alta frequência, ou seja, pela ecolocalização. Eles possuem nas orelhas um aparato membranoso e sensível denominado trago, que têm a função de receber as ondas sonoras e intensifica-las (PERACCHI et al., 2011). É desse modo que encontram alimentos e desviam de obstáculos. Além disso, eles utilizam o som para as relações intra-específicas, como comunicação, acasalamento e agressão, e alguns desses sons emitidos não são audíveis para os seres humanos.

De acordo com um dos alunos entrevistados, "se balançarmos uma vara de pescar, atraímos os morcegos". Na pesquisa de Scravoni et al. (2008), algumas crianças moradoras de área urbana relataram que têm o hábito de movimentar varas de bambu com rapidez, atingindo e derrubando-os em voo. Andrade e Talomoni (2015), entrevistaram estudantes que também comentaram que já haviam matado morcegos ao girar o bambu no ar, justificando que esses animais são ruins e disseminam doenças. Cabral (2006) entrevistou professores de ciências e biologia e 2,5\% relataram que agitar um pedaço de pau pode atraí-los.

Com relação às características, tem destaque o mito de que os morcegos são cegos. Segundo Reis et al. (2007) como animais noturnos, eles possuem poucos cones na retina, uma estrutura que está associada com a percepção de cores. Contudo, não são cegos, e ainda que todas as famílias brasileiras utilizem a ecolocalização para a orientação, algumas espécies de frugívoros também utilizam a visão.

Alguns alunos ao responderem a questão expressaram sentimentos com relação a esses animais, como por exemplo, afeto, aversão e indiferença. Um dos entrevistados relatou que "a presença deles é muito ruim", relacionando esses animais com mau agouro. 
Filmes e desenhos foram citados por 09 vezes. Para Prokop et al. (2009), a mídia tende a representar os morcegos como animais a serem temidos. De acordo com Caparros e Junior (2015), filmes novelas e desenhos muitas vezes exaltam apenas seus aspectos negativos, além de frequentemente associar esses animais a personagens de vampiros. Segundo os mesmos autores isso pode interferir na percepção que as pessoas têm sobre o grupo, já que a mídia possui forte influência sobre a percepção e comportamento da sociedade.

\section{Conclusões}

O estudo da percepção dos alunos com relação às questões ambientais é uma ferramenta de grande importância quando aplicado com o objetivo de se conhecer a realidade do público-alvo, seus interesses, anseios, além dos mitos e crenças populares que os mesmos trazem para a sala de aula. Quando se trabalha com vários alunos, deve-se levar em consideração que se trata de uma turma comumente heterogênea, com uma bagagem de conhecimentos prévios normalmente compostos por vivências, crenças transmitidas de geração em geração, influência da mídia e percepções individuais.

Nessa pesquisa foi investigada a percepção dos alunos com relação aos morcegos, grupo de animais cercado de mitos e superstições e que normalmente sofre com a rejeição pela sociedade, que vê esses animais como sujos, vampiros, disseminadores de doenças etc. Contudo, a pesquisa da percepção do público-alvo pode ser aplicada quando se deseja trabalhar com diversos assuntos, ou ainda quando se deseja analisar a efetividade de um programa de Educação Ambiental após o mesmo ser aplicado.

No presente estudo foi possível verificar que a maioria dos estudantes possui conhecimento quanto à classificação dos morcegos, assim como sua alimentação e importância ecológica, mostrando que a percepção dos alunos com relação a esses animais é positiva. Esse resultado pode ter sido consequência da observação desses animais no ambiente urbano, como em árvores frutíferas e ao redor de postes de iluminação capturando insetos. Entretanto, muitos mitos são levados para a sala de aula, como quando relatam que os morcegos são vampiros ou ratos velhos e cegos.

Após realizada uma pesquisa da percepção ambiental, sugere-se, para esclarecer informações equivocadas e desmistificar os morcegos, a realização de atividades educativas como oficinas, palestras e atividades lúdicas que proporcionem uma maior aproximação das crianças com esses animais. Tais atividades podem se basear no estudo gerado para identificar quais as principais lacunas a serem preenchidas e, dessa forma, conduzir as atividades de forma eficaz, produzindo resultados significativos com base em conhecimentos prévios. 


\section{Referências}

ANDRADE, T. Y. I.; TALAMONI, J. L. B. Morcegos, anjos ou demônios? Desmistificando os morcegos em uma trilha interpretativa. Revista SimbioLogias. Botucatu, v.8, n.11, p. 179-187, Dez/2015.

BRASIL. Lei no 9.605, de 12 de fevereiro de 1998 - Dispõe sobre as sanções penais e administrativas derivadas de condutas e atividades lesivas ao meio ambiente, e dá outras providências. Disponível em: <http://www.planalto.gov.br/ ccivil 03/Leis/L9605.htm>. Acesso em: 15 março 2018.

BRASIL. Lei no 9.795 de abril de 1999. Dispõe sobre a Educação Ambiental e institui a Política Nacional de Educação Ambiental. Brasília, DF, 1999. Disponível em: <http://www.planalto.gov.br/ccivil 03/Leis/L9795.htm>. Acesso em: 14 agosto 2019.

BEZERRA, Y. B. S.; PEREIRA, F. S. P.; SILVA, A. K. P.; MENDES, D. G. P. S. Análise da percepção ambiental de estudantes do Ensino Fundamental II em uma escola do município de Serra Talhada (PE). Revista Brasileira de Educação Ambiental. São Paulo, v.9, n.2, p.472-488, 2014.

CABRAL, L. B. Morcegos e a educação para a ciência: uma intervenção com professores de ciências e biologia. 2006. Monografia (Bacharelado em Ciências Biológicas) - Universidade Federal do Paraná, Paraná, 2006.

CAPPARROS, E. M.; JUNIOR, C. A. O. M. A representação social sobre morcegos apresentada pela mídia Brasileira. Revista Contexto \& Educação. ljuí, v.30, n.97, p. 94-116, 2015.

CUNHA, T. S.; ZENI, A. L. B. A representação social de meio ambiente para alunos de ciências e biologia: subsídio para atividades em Educação Ambiental. Revista Eletrônica do Mestrado em Educação Ambiental. Rio Grande, v.18, p.399-414, Jan/Jun, 2007.

ESBÉRARD, C. E.L., CHAGAS, A.S., LUZ, E. M.; CARNEIRO, R. Pesquisa com público sobre morcegos. Chiroptera Neotropical, v.1, n. 2, p.44-45, 1996.

ESTEVAM, C. S.; GAIA, M. C. M. Concepção ambiental na educação básica: subsídios para estratégias de Educação Ambiental. Revista Brasileira de Educação Ambiental. São Paulo, v.12, n.1, p.195-208, 2017.

FAGGIONATO, S. Percepção ambiental. 2007. Disponível em: $<$ http://educar.sc.usp.br/biologia/textos/m a txt4.html>. Acesso em: 20 maio. 2018.

FERREIRA, M. S.; BORGES, A. S. Histoplasmose. Revista da Sociedade Brasileira de Medicina Tropical. v.42, n.2, p.192-198, mar-abr. 2009

FILHO, T. P. S.; SILVA, L. A. M.; SILVA, R. R.; OLIVEIRA, P. J. A.; OLIVEIRA, J. C. T.; SILVA, E. M. V. G.; CUNHA, M. T. S. A influência do ensino e aprendizagem na formação de conceitos sobre morcegos entre alunos de $5^{\underline{a}} \mathrm{e}$ $6^{\underline{a}}$ séries em Vitória de Santo Antão, Pernambuco. Chiroptera Neotropical. v.16, n.1 (Supl.), p.11-113, abr.2010. 
GOMES, M. C. B.; NETO, E. M. C.; ALVAREZ, M. R. V. Ethnozoology of bats (Mammalia, Chiroptera) in Feira de Santana Municipality, Bahia State, Northeastern Brazil. Brazilian Journal of Biological Sciences. João Pessoa, v.4, n.7, p.147-156, 2017.

GONÇALVES, A. M. M.; SEPÚLVEDA, P. S.; CARVALHO, N. S.; SILVA, L. A. Morcegos: Diagnóstico do conhecimento da população em áreas endêmicas da região metropolitana de São Paulo. Revista Educação Ambiental em ação. n.57, ano XV, set-nov 2016.

KANDA, C. Z.; ANDRADE, J. A. C.; ARAÚJO, C. A. M.; MEIRELLES, P. G. Trilha sensitiva como estratégia de ensino do bioma Cerrado. Revista Brasileira de Educação Ambiental. São Paulo, v.9, n.1, p.23-36, 2014.

KNIGHT, A. J. "Bats, snakes and spiders, Oh my!": How aesthetic and negativistic attitudes, and other concepts predict support for species protection. Journal of Environmental Psychology. v. 28, n.1, p. 94-103, 2008.

KUBIATKO, M.; PROKOP, P. Pupils' misconceptions about mammals. Journal of Baltic Science Education, v.6, n.1, p.5-14, 2007.

KUNZ, T. M.; TORREZ, E. B.; BAUER, D.; LOBOVA, T.; FLEMING, T. H. Ecosystem services provided by bats. Annals of the New York Academy of Sciences. v.1223, n.1, p.1-38, 2011.

LAURINDO, R. S.; NOVAES, R. L. M. Desmistificando os morcegos. Monte Belo: ISMECN, 2015.

LEAL, J. C. P.; NUNES, E. R. M. A Percepção ambiental: um subsídio para os trabalhos em Educação Ambiental In: ENCONTRO NACIONAL DE PESQUISA EM EDUCAÇÃO EM CIÊNCIAS, 4., 2003. Bauru, Anais... Bauru: Associação Brasileira de Pesquisa em Educação em Ciências, 2003.

LIMA, I. P. Espécies de morcegos (Mammalia, Chiroptera) registradas em parques nas áreas urbanas do Brasil e suas implicações no uso deste ambiente. In: REIS, N. R.; PERACCHI, A. L.; SANTOS, G. A. S. D. (Org.). Ecologia de Morcegos. Londrina: Technical Books, 2008. p.71-85.

NOLAN, J. M.; ROBBINS, M. C. Emotional Meaning and the Cognitive Organization of Ethnozoological Domains. Journal of Linguistic Anthropology. n.11, v.2, p.1-9, 2001.

NOVAES, R. L. M.; JUNIOR, L. F. M.; DUARTE, A. C.; FAÇANHA, A. C. Pesquisa de opinião sobre os morcegos com frequentadores do Parque da Prainha, Rio de Janeiro. Revista Educação Ambiental em ação, n.25, ano VII, set-nov 2008.

PAIVA, V. M. F. Educação Ambiental: impacto na percepção e mudança de atitudes em relação aos morcegos. 2010. 54 f. Dissertação (Mestrado em Ecologia e Gestão Ambiental) - Faculdade de Ciências, Universidade de Lisboa, Lisboa, 2010. 
PERACCHI, A. L.; LIMA, I. P.; REIS, N. R.; NOGUEIRA, M. R.; FILHO, H. O. Ordem Chiroptera. In: REIS, N. R.; PERACCHI, A. L.; PEDRO, W. A.; LIMA, I. P. (Org.).Mamíferos do Brasil. 2. ed. Londrina: Nelio R. dos Reis, 2011. Cap.7, p.155-217.

PROKOP, P.; FANČOVIČOVÁ, J.; KUBIATKO, M. Vampires Are Still Alive: Slovakian Students' Attitudes toward Bats. Anthrozoös. v.22, n.1, p.19-30, 2009.

PROKOP, P.; TUNNICLIFFE, S. D. "Disgusting" animals: primary school children's attitudes and myths of bats and spiders. Eurasia Journal of Mathematics, Science and Technology Education. v.4, n.2, p.87-97, 2008.

REIS, N. R.; SHIBATTA, O. A.; PERACCHI, A. L.; PEDRO, W. A.; LIMA, I. P. Sobre os morcegos brasileiros. In: REIS, N. R.; PERACCHI, A. L.; PEDRO, W. A.; LIMA, I. P. (Org.) Morcegos do Brasil. Londrina: Nelio R. dos Reis, 2007. Cap. 1, p.13-16.

SCAVRONI, J; PALEARI, L. M.; UIEDA, W. Morcegos: Realidade e fantasia na concepção de crianças de área urbana de Botucatu, SP. Revista SimbioLogias. Botucatu, v.1, n.2, p.1-18. 2008.

SOUSA, C. A. F.; ALVES, A. F.; ANDRADE, T. M.; NICODEMO, S. C. T. S.; VITORINO, G. O. A percepção ambiental de atores sociais de escolas públicas e privadas, em um bairro de João Pessoa (PB). Revista Brasileira de Educação Ambiental. São Paulo, v.12, n.4, p.180-191, 2017.

UIEDA, W. Pesquisas com morcegos no Brasil: quando, quantos e como matar? In: IV Encontro Brasileiro para Estudo de Quirópteros, 2011, Maringá. Anais... Maringá: Chiroptera Neotropical, 2011, p. 17.

VIEIRA, M. R. M.; BITENCOURT, K.; ZANON, A. M. Percepção sobre a fauna por estudantes do 5o ano do ensino fundamental, Rio Verde de MT- MS: Contribuições para o ensino de ciências e a Educação Ambiental. In: SIMPÓSIO NACIONAL DE ENSINO DE CIÊNCIA E TECNOLOGIA, 4., 2014. Ponta Grossa, Anais... Ponta Grossa: CASTILHO, R.M.; SILVEIRA, F.; MAINGINSKI, F.E.; BERSSANETTE, J.H., 2014. 
Apêndice 1: Questionário sobre a percepção dos alunos com relação aos morcegos.

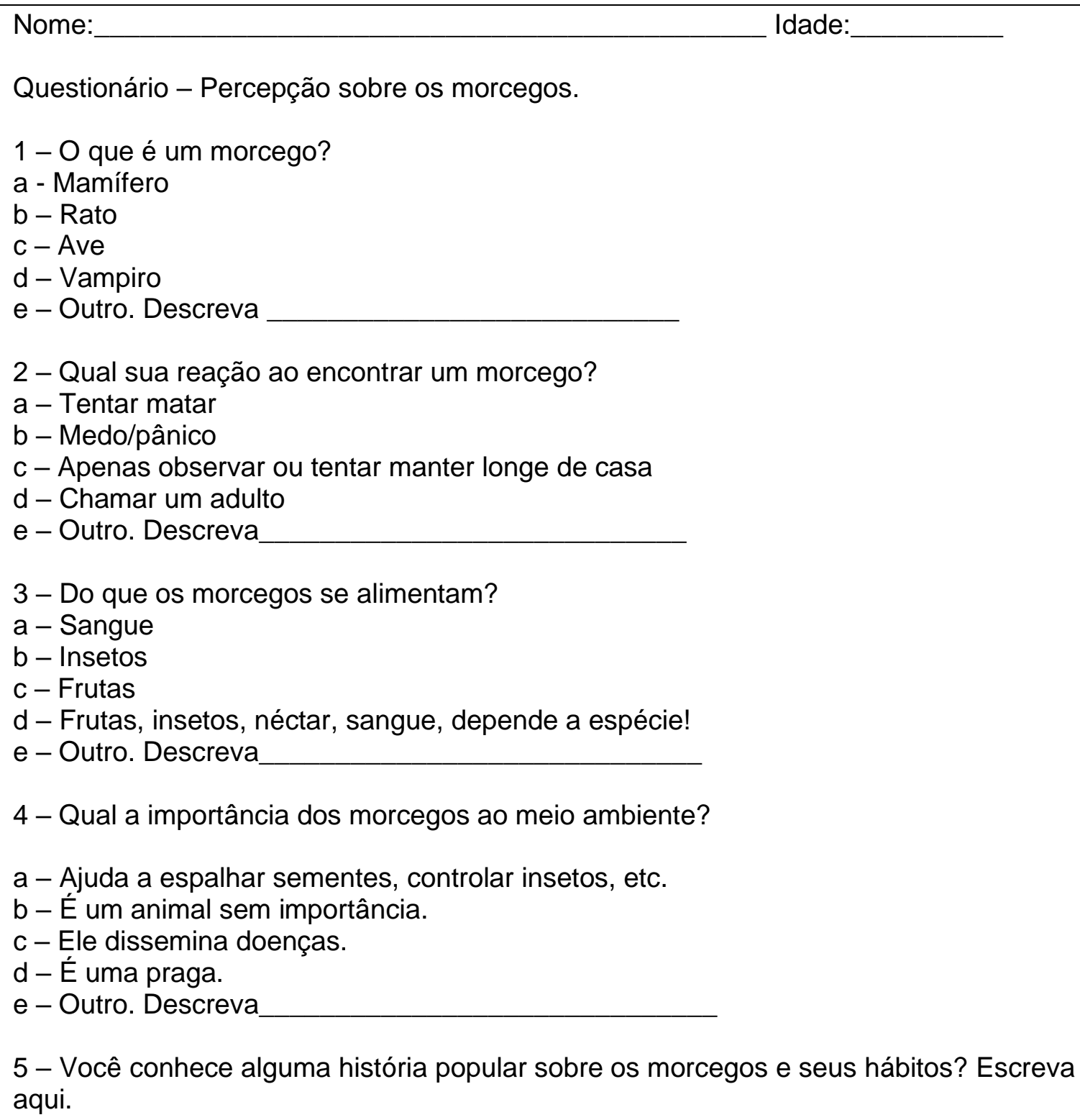
aqui. 